\title{
CONDIÇÕES AMBIENTAIS EM GALPÃO CON VENCIONAL TELADO PARA GALINHAS POEDEIRAS HYLINE W-36
}

Doi:http://dx.doi.org/10.1590/1809-4430-Eng.Agric.v35n 1p 1-10/2015

\section{DIAN LOURENÇONI ${ }^{1}$, TADAYUKI YANAGI JUNIOR ${ }^{2}$, DANIELA D. DE OLIVEIRA ${ }^{3}$, ALESSANDRO T. CAMPOS ${ }^{4}$, RENATO R. DE LIMA ${ }^{5}$}

\begin{abstract}
RESUMO: Devido às ocorrências dos vírus de influenza aviária (H5N1 e H7N2), estudos relacionados à biosseguridade têm-se intensificado, e uma das soluções discutidas é o uso de tela para cercar completamente o perímetro dos galpões, visando a evitar o contato das galinhas poedeiras alojadas com outras aves. Desta forma, o presente trabalho teve como objetivo avaliar e comparar a utilização de tela cercando o perímetro de galpões convencionais de poedeiras, sobre o ambiente acústico e aéreo no interior da instalação. A pesquisa foi realizada em uma granja comercial para produção de ovos, localizada no sul do Estado de Minas Gerais, e foi conduzida em um galpão aberto, que teve a metade de sua área cercada por tela e a outra metade mantida totalmente aberta. Foram alojadas galinhas poedeiras da linhagem Hyline $W$-36, sendo analisadas as variáveis de intensidade sonora, concentração de amônia $\left(\mathrm{NH}_{3}\right)$ e concentração de dióxido de carbono $\left(\mathrm{CO}_{2}\right)$. As variáveis foram coletadas em seis pontos de medição, em cada região (com e sem tela), dois em cada corredor (norte, central e sul). Os resultados indicaram que o uso de tela não alterou o nível de ruído e as concentrações de $\mathrm{NH}_{3}$ e de $\mathrm{CO}_{2}$ no interior do galpão analisado. Contudo, os níveis mensurados foram inferiores àqueles que ofereceriam riscos à saúde das aves e dos trabalhadores, podendo-se concluir que o uso de tela não influenciou negativamente no ambiente aéreo do galpão.
\end{abstract}

PALAVRAS-CHAVE: bios seguridade, ruído, amônia, dióxido de carbono, poedeiras.

\section{ENVIRONMENTAL CONDITIONS IN A CONVENTIONAL SCREENED POULTRY SHED}

\begin{abstract}
Avian influenza viruses ( $\mathrm{H} 5 \mathrm{~N} 1$ and $\mathrm{H} 7 \mathrm{~N} 2)$ triggered a great number of studies on biosafety, and one of the discussed solutions is the use of screen to enclose completely the poultry house perimeter, since it can avoid the contact of laying hens with other birds. Thus, the present study aimed to evaluate and compare the use of screen enclosing a conventional laying house perimeter by assessing acoustic and aerial environment inside the facility. The research was performed in a commercial egg production farm located in Southern Minas Gerais State, Brazil. It was carried out in an open facility, in which half area was enclosed by screen and the other half was maintained completely open. Hyline W-36 laying hens were housed. Sound intensity, ammonia concentration $\left(\mathrm{NH}_{3}\right)$ and carbon dioxide concentration $\left(\mathrm{CO}_{2}\right)$ were analyzed as variables. These variables were collected from six measuring points in each region (with and without screen), two in each alley (north, central and south). The results indicated that the use of screen did not alter the noise level, $\mathrm{NH}_{3}$ and $\mathrm{CO}_{2}$ concentrations inside the analyzed poultry house. However, the levels measured were smaller than to the thresholds that can offer health risks to birds and workers. Therefore, it may be concluded that the use of screen did not influence negatively the facility aerial environment.
\end{abstract}

KEYWORDS: biosafety, noise, ammonia, carbon dioxide, laying hens.

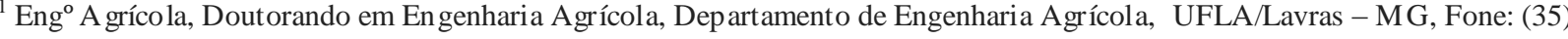
9136-9613, dlourenconi@hotmail.com.

${ }^{2}$ Eng $^{\circ}$ A grícola, Prof. Doutor, Departamento de Engenharia Agrícola, UFLA/Lavras - MG, yanagi @deg.ufla.br.

${ }^{3}$ Medica Veterinária, Doutora, Aviário Santo Antonio, ASA/Nepomuceno - MG, danidoli@ hotmail.com.

${ }^{4}$ Eng $^{\circ}$ A grícola, Prof. Doutor, Departamento de Engenharia Agrícola, UFLA/Lavras - MG, campos@ deg.ufla.br.

${ }^{5}$ Zootecnista, Prof. Doutor, Departamento de Ciências Exatas, UFLA/Lavras - MG, rrlima@ dex.ufla.br. 


\section{INTRODUÇÃO}

Existe constante preocupação em garantir que as instalações avícolas forneçam ambiente saudável para aves e trabalhadores, sendo este um fator agregador de valor aos produtos avícolas. A maioria das propriedades avícolas brasileiras que trabalham com sistema de confinamento, gera acúmulo de gases, como amônia $\left(\mathrm{NH}_{3}\right)$ e dióxido de carbono $\left(\mathrm{CO}_{2}\right)$, prejudicando a saúde dos animais e trabalhadores. Ademais, o ruído (nível de pressão sonora) produzido pelas aves e pelos equipamentos dentro das instalações pode causar prejuízos aos trabalhadores. A avaliação da qualidade do ar em galpões para galinhas poedeiras ocorre com foco na saúde dos animais alojados e dos trabalhadores que permanecem até oito horas por dia nesse ambiente de trabalho (NÄ̈̈S et al., 2007; MENEGALI et al., 2009; MOURA et al., 2010; VIGODERIS et al., 2010).

Os gases mais comumente encontrados em galpões para galinhas poedeiras são $\mathrm{NH}_{3}$ e $\mathrm{CO}_{2}$, cujos limites permissíveis de concentração em instalações avícolas são de 20 ppm (WATHES et al., 1998; FURTADO et al., 2010; CARVALHO et al., 2011) e 3.000 ppm (WATHES et al., 1998), respectivamente.

No Brasil, de acordo com a NR-15 (MTE, 1990), os limites máximos de concentração de $\mathrm{NH}_{3}$ e $\mathrm{CO}_{2}$ para exposição de trabalhadores é de $20 \mathrm{ppm}$ e $3.900 \mathrm{ppm}$, respectivamente. Com relação ao ruído, a NR-15 (MTE, 1990) determina os limites de tolerância para humanos, sendo que, para exposição diária de 8 horas, o nível máximo permitido é de $85 \mathrm{~dB}$ (A). Por sua vez, a exposição do nível de ruído de $115 \mathrm{~dB}$ (A) é de, no máximo 7 minutos, não sendo permitida exposição a níveis de ruído acima deste limite para indivíduos que não estejam adequadamente protegidos com EPI (Equipamento de Proteção Individual).

NÄÄS et al. (2001) estudaram os níveis de ruído na produção de matrizes pesadas, verificando que os valores médios estavam abaixo dos níveis recomendados pela NR-15 (MTE, 1990), porém no galpão de produção de ovos o nível de ruído atingiu pico de $95,1 \mathrm{~dB}$, levando os autores a recomendarem o uso de protetores auriculares a fim de se atender à legislação brasileira de insalubridade. Segundo NASCIMENTO et al. (2007), a poluição sonora é, depois da poluição do ar e da água, a que afeta o maior número de pessoas. Diante disto, torna-se imperativo avaliar o ambiente acústico a que o trabalhador está submetido (BRAVALHERI et al., 2010; YANAGI JUNIOR et al., 2012). De acordo com SARAZ et al. (2010), o que determina a qualidade ambiental dentro das instalações avícolas são os efeitos combinados das variáveis ambientais, como concentração de $\mathrm{CO}_{2}$ e $\mathrm{NH}_{3}$, nível de ruído, temperatura do ar, umidade relativa e taxa de ventilação.

Devido às ocorrências dos vírus da influenza aviária (H5N1 e H7N2), cujo principal fator de risco é o contato com animais portadores ou ambientes contaminados, têm-se intensificado os estudos relacionados à biossegurança, discutindo-se soluções que possam minimizar os riscos de contaminação de galinhas poedeiras alojadas em sistema convencional (galpões abertos) por outras aves, como, por exemplo, pássaros migratórios ou regionais que possam estar infectados com estes vírus. Uma das soluções discutidas é o uso de tela para cercar completamente o perímetro dos galpões, medida de biossegurança que visa a evitar o contato das galinhas poedeiras alojadas com outras aves.

De acordo com o artigo 14 da Instrução Normativa IN56 (MAPA, 2007), revogada pela Instrução Normativa $N^{\circ} 36$, de 2012, do Ministério da Agricultura (MAPA, 2012), todos os estabelecimentos avícolas comerciais devem ser construídos com materiais que permitam limpeza e desinfecção e que os mesmos sejam providos de proteção ao ambiente externo, com instalação de telas com malha de medida não superior a 1,0 polegada ou $2,54 \mathrm{~cm}$, à prova de entrada de pássaros, animais domésticos e silvestres.

Diante do exposto, objetivou-se, com o presente trabalho, comparar o ambiente acústico e aéreo no interior de galpões convencionais para alojamento de galinhas poedeiras, cercados ou não por tela. 


\section{MATERIAL E MÉTODOS}

O experimento foi desenvolvido em uma granja comercial para produção de ovos, localizada no sul do Estado de Minas Gerais, no período de junho a novembro de 2012. Foi utilizado um galpão convencional de $7 \mathrm{~m}$ x $120 \mathrm{~m}$, com cobertura de telhas de cimento amianto, pé-direito de 2,50 m e orientação leste-oeste, tendo o galpão metade de sua área cercada por tela (incluindo a parte interna que dividia as duas regiões) e a outra metade mantida totalmente aberta (Figura 1A). Neste galpão, foram alojadas galinhas poedeiras da linhagem Hyline $W$-36, com idades a partir de 71 semanas, no início do experimento. Durante o período experimental, as aves receberam água e ração ad libitum, com coleta de ovos realizada duas vezes ao dia. As aves foram submetidas a um programa de luz de 17 horas de claro e 7 horas de escuro.

A tela utilizada para cercar parte do galpão era de polietileno de alta densidade (HDPE - High density polyethylene), na cor preta, com malha de 2,0 cm de diâmetro, que está em conformidade com a Instrução Normativa IN56 (MAPA, 2007) (Figura 1B). As telas de polietileno de alta densidade foram desenvolvidas para substituir as telas metálicas e galvanizadas e atender a características que estas últimas não oferecem. Dentre as características apresentadas, podem destacar-se a variedade de abertura de malhas, a facilidade de instalação, não machucam as aves, não enferrujam e são resistentes a produtos utilizados na desinfecção química.

A.

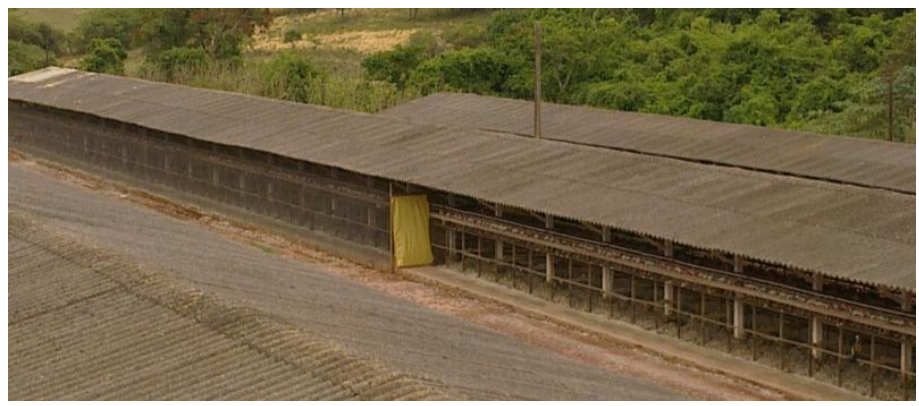

B.

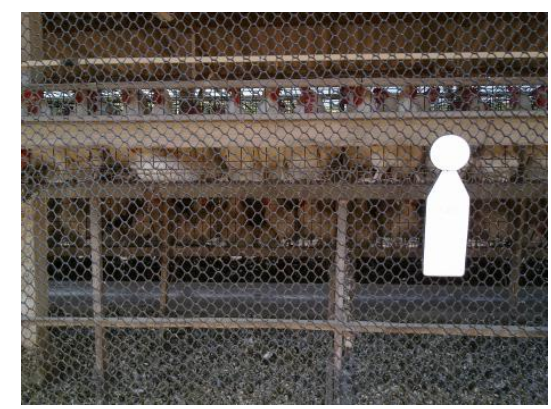

FIGURA 1. Galpão para poedeiras comerciais com metade de seu perímetro externo cercado com tela (A) e detalhe da tela em PEAD de 2,00 cm de malha (B). Comme rcial laying hen facility with half external perimeter enclosed by screen (A) and detail of the 2.00cm mesh HDPE screen (B).

Os procedimentos adotados com os animais nesta pesquisa foram aprovados pelo Comitê de Ética em Experimentação Animal da Universidade Federal de Lavras, protocolo no 026/12.

Seis pontos de medição em cada região e dois em cada corredor (norte, central e sul) foram usados para a caracterização das variáveis acústicas e aéreas (Figuras 2, 3 Ae 3B). 


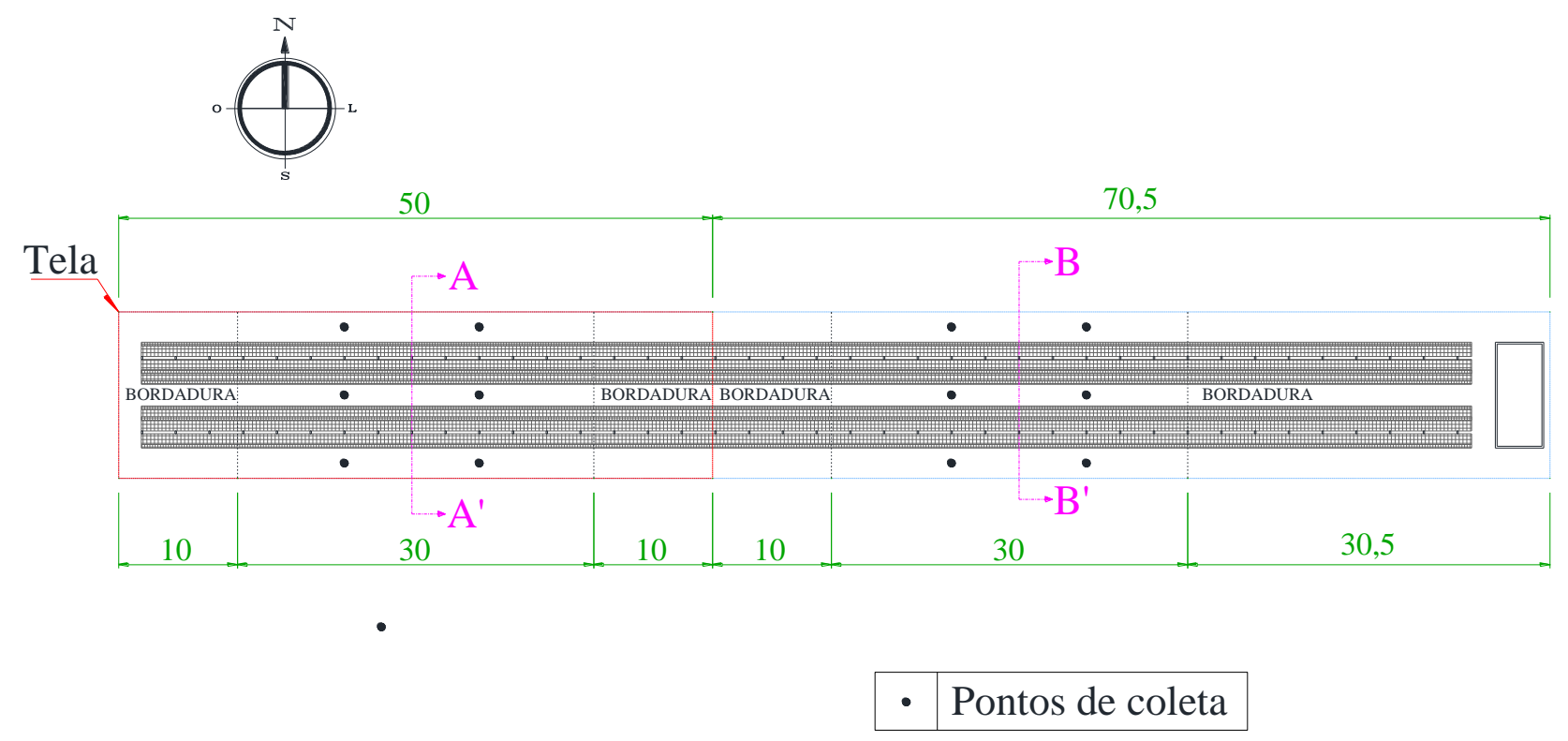

FIGURA 2. Desenho esquemático da distribuição dos pontos de coleta no galpão (em metros). Schematic design of the sampling point distribution within the facility (meters)

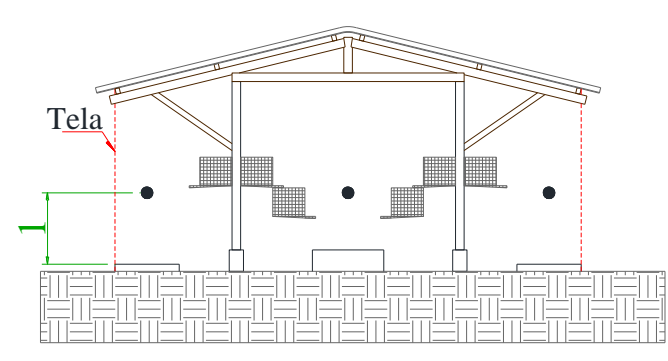

A) Corte AA'

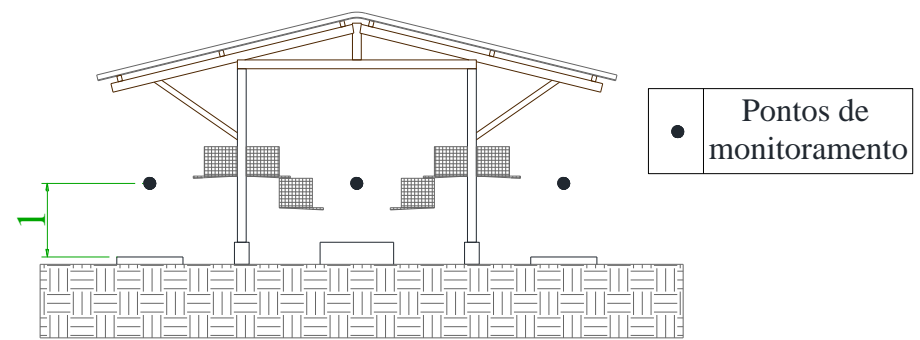

B) Corte BB'

FIGURA 3. Cortes do galpão (em metros). Shed cross-section (meters)

O nível de ruído foi coletado por meio de decibelímetros registradores (Instrutherm, modelo DEC-480, precisão de $\pm 1,5 \mathrm{~dB}$ ) no circuito de resposta lenta e de equalização "A", expressos em $\mathrm{dB}(\mathrm{A})$, sendo que o protetor de ventos dos decibelímetros foi utilizado em todas as medições. Relacionadas ao ambiente aéreo, as concentrações de amônia $\left(\mathrm{NH}_{3}\right)$ e dióxido de carbono $\left(\mathrm{CO}_{2}\right)$ foram coletadas por meio de sensores portáteis (para $\mathrm{NH}_{3}$ - Instrutherm, modelo DG-200, precisão de $\pm 5 \%$ F. S.; e para $\mathrm{CO}_{2}$ - Testo, modelo 535, precisão $\pm 50 \mathrm{ppm}$ para concentrações de 0 a 5.000 ppm e \pm 100 ppm para concentrações de 5.000 a 9.999 ppm).

A variável ruído foi coletada a cada 10 minutos, no período de $8 \mathrm{~h}$ às $20 \mathrm{~h}$, e as variáveis do ambiente aéreo $\left(\mathrm{NH}_{3}\right.$ e $\left.\mathrm{CO}_{2}\right)$ foram coletadas em intervalos de $2 \mathrm{~h}$, das 8 às $20 \mathrm{~h}$, uma vez por semana durante o período de junho a novembro de 2012, totalizando 22 dias de medição. Estas duas últimas variáveis foram coletadas com um único sensor para cada variável, sendo essas coletas feitas ponto a ponto, seguindo sempre o sentido de caminhamento dos corredores, permitindo que os tempos de coleta nos pontos localizados na região do galpão com tela e sem tela fossem mínimos. Este procedimento permitiu a comparação estatística das variáveis previamente citadas nas regiões com e sem tela. Todas as medições foram realizadas, respectivamente, à altura média das gaiolas de 1,0 m (Figuras 3A e 3B).

O experimento foi instalado seguindo o delineamento em blocos casualizados (DBC), num esquema de parcelas subsubdivididas. Na parcela, foram alocados os tratamentos testados, ou seja, região do galpão cercado com tela e sem tela, totalizando dois tratamentos. $O$ fator corredor foi alocado na subparcela, e o fator tempo foi alocado na subsubparcela, sendo coletados dados a cada 
2 horas, das $8 \mathrm{~h}$ às $20 \mathrm{~h}$, totalizando 7 horários de coleta. As medições foram realizadas durante 22 dias não consecutivos (medições realizadas uma vez por semana durante o período experimental), sendo que cada dia foi considerado como bloco. As análises estatísticas foram processadas pelo software SAS (2012).

\section{RESULTADOS E DISCUSSÃO}

De acordo com os dados coletados no interior do galpão, a variável intensidade sonora teve interação significativa para tela $x$ corredor $(p<0,01$, teste $F)$, corredor $x$ período $(p<0,01$, teste $F)$ e tela $\mathrm{x}$ período $(\mathrm{p}<0,05$, teste $\mathrm{F})$. Entretanto, o uso da tela para cercar o perímetro externo do galpão não interferiu nos níveis de ruído observados nas regiões com e sem tela (Tabela 1). Por sua vez, ao se comparar os níveis de ruído entre os corredores, o central apresentou maiores valores (Tabela 1). Este resultado deveu-se ao fato de os sensores localizados na região central estarem entre duas fontes de ruído, ou seja, as baterias de gaiolas para alojamento das aves. $\mathrm{Na}$ região com tela, observa-se que o corredor sul apresentou maiores valores de ruído que o corredor norte. Este resultado deve-se ao fato de esta face do galpão estar próxima a uma composteira, onde se verificou a aglomeração de urubus, fazendo com que as galinhas ficassem mais agitadas nesta região.

TABELA 1. Valores médios do nível de ruído $(\mathrm{dB})$ nos tratamentos com e sem tela $\mathrm{x}$ corredor. Mean noise levels $(\mathrm{dB})$ in the treatments with and without screen $x$ alley.

\begin{tabular}{ccc}
\hline \multirow{2}{*}{ Corredor } & \multicolumn{2}{c}{ Utilização de tela } \\
\cline { 2 - 3 } & Com & Sem \\
\hline Norte & 63,0 a A & 63,5 a A \\
Central & $67,1 \mathrm{c} \mathrm{A}$ & $66,7 \mathrm{~b} \mathrm{~A}$ \\
Sul & $63,7 \mathrm{~b} \mathrm{~A}$ & $63,4 \mathrm{a} \mathrm{A}$ \\
\hline
\end{tabular}

Médias seguidas de letras distintas, maiúsculas na linha e minúsculas na coluna, diferem entre si, pelo teste de Tukey, ao nível de 5\% de probabilidade. $\mathrm{CV}=2,12 \%$.

Conforme pode ser observado na Tabela 2, relacionando-se ao horário do dia, observou-se que o nível de ruído diminui de intensidade no decorrer do dia, devendo-se isto ao fato de que as aves realizam postura predominantemente no período da manhã, e durante a postura elas realizam vocalização.

TABELA 2. Valores médios de nível de ruído $(\mathrm{dB})$ nos tratamentos com e sem tela ao longo do período de avaliação. Mean noise levels $(\mathbf{d B})$ in the treatments with and without screen throughout the evaluation period.

\begin{tabular}{ccc}
\hline \multirow{2}{*}{ Período } & \multicolumn{3}{c}{ Utilização de tela } \\
\cline { 2 - 3 } & Com & Sem \\
\hline $\mathbf{1 0 : 0 0}$ & $72,7 \mathrm{e} \mathrm{A}$ & $72,5 \mathrm{e} \mathrm{A}$ \\
$\mathbf{1 2 : 0 0}$ & $69,2 \mathrm{~d} \mathrm{~A}$ & $68,8 \mathrm{~d} \mathrm{~A}$ \\
$\mathbf{1 4 : 0 0}$ & $64,7 \mathrm{c} \mathrm{A}$ & $64,4 \mathrm{c} \mathrm{A}$ \\
$\mathbf{1 6 : 0 0}$ & $63,1 \mathrm{~b} \mathrm{~A}$ & $63,4 \mathrm{bc} \mathrm{A}$ \\
$\mathbf{1 8 : 0 0}$ & $60,0 \mathrm{a} \mathrm{A}$ & $60,4 \mathrm{a} \mathrm{A}$ \\
$\mathbf{2 0 : 0 0}$ & $62,4 \mathrm{~b} \mathrm{~A}$ & $62,5 \mathrm{~b} \mathrm{~A}$ \\
& $60,2 \mathrm{a} \mathrm{A}$ & $59,7 \mathrm{a} \mathrm{A}$ \\
\hline
\end{tabular}

Médias seguidas de letras distintas, maiúsculas na linha e minúsculas na coluna, diferem entre si, pelo teste de Tukey, ao nível de 5\% de probabilidade. $\mathrm{CV}=2,01 \%$.

Como pode ser observado na Tabela 3, o corredor sul diferenciou-se do corredor norte apenas no período das 16 horas, resultado que se deve ao fato de esta face do galpão estar próxima a uma composteira, e que após o término do serviço dos trabalhadores da granja, por volta das 15 horas e 30 minutos, verificou-se uma aglomeração de urubus nesta composteira, fazendo com que as galinhas ficassem mais agitadas nesta região. 
Os valores médios de ruído observados dentro do galpão estão abaixo dos níveis recomendados pela NR-15 (MTE, 1990), que é de 85 dB para uma jornada de trabalho de 8 horas. Esses valores são semelhantes aos encontrados por ROCHA et al. (2010), FURTADO et al. (2011) e YANAGI JUNIOR et al. (2011).

TABELA 3. Valores médios de nível de ruído (dB) nos corredores ao longo do período de avalição. Mean noise levels $(\mathrm{dB})$ in the alleys throughout the evaluation period.

\begin{tabular}{cccc}
\hline \multirow{2}{*}{ Período } & \multicolumn{3}{c}{ Corredor } \\
\cline { 2 - 4 } & Norte & Central & Sul \\
\hline $\mathbf{0 8 : 0 0}$ & $71,7 \mathrm{e} \mathrm{A}$ & $74,4 \mathrm{e} \mathrm{B}$ & $71,6 \mathrm{e} \mathrm{A}$ \\
$\mathbf{1 0 : 0 0}$ & $68,0 \mathrm{~d} \mathrm{~A}$ & $71,0 \mathrm{~d} \mathrm{~B}$ & $68,0 \mathrm{~d} \mathrm{~A}$ \\
$\mathbf{1 2 : 0 0}$ & $63,0 \mathrm{~b} \mathrm{~A}$ & $66,9 \mathrm{c} \mathrm{B}$ & $63,7 \mathrm{c} \mathrm{A}$ \\
$\mathbf{1 4 : 0 0}$ & $61,9 \mathrm{bc} \mathrm{A}$ & $65,4 \mathrm{bc} \mathrm{B}$ & $62,5 \mathrm{bc} \mathrm{A}$ \\
$\mathbf{1 6 : 0 0}$ & $58,1 \mathrm{a} \mathrm{A}$ & $63,0 \mathrm{a} \mathrm{C}$ & $59,5 \mathrm{a} \mathrm{B}$ \\
$\mathbf{1 8 : 0 0}$ & $61,3 \mathrm{bc} \mathrm{A}$ & $64,7 \mathrm{~b} \mathrm{~B}$ & $61,3 \mathrm{~b} \mathrm{~A}$ \\
$\mathbf{2 0 : 0 0}$ & $58,6 \mathrm{a} \mathrm{A}$ & $63,0 \mathrm{a} \mathrm{B}$ & $58,3 \mathrm{a} \mathrm{A}$ \\
\hline
\end{tabular}

Médias seguidas de letras distintas, maiúsculas na linha e minúsculas na coluna, diferem entre si, pelo teste de Tukey, ao nível de 5\% de probabilidade. $\mathrm{CV}=2,01 \%$.

Para o nível de concentração de $\mathrm{NH}_{3}$, observou-se diferença significativa ( $\mathrm{p}<0,01$, teste $\mathrm{F}$ ) para o tratamento de tela e interação entre os tratamentos corredor $\mathrm{x}$ período. $\mathrm{O}$ uso da tela, independentemente do corredor e do período, para cercar o perímetro externo do galpão, resultou em valores médios de concentração de $\mathrm{NH}_{3}$ superiores aos observados na região sem tela (Tabela 4). Este resultado deve-se à redução do fluxo de ar através do galpão avícola, que segundo MATTOS (2007) depende, dentre outros fatores, da resistência ao fluxo de ar oferecido pelas aberturas e obstruções internas.

TABELA 4. Valores médios de concentração de $\mathrm{NH}_{3}$ ( $\mathrm{ppm}$ ) nos tratamentos com e sem tela. Mean $\mathrm{NH}_{3}$ concentration (ppm) in the treatments with and without screen.

\begin{tabular}{ccc}
\hline Tela & Com & Sem \\
\hline & $0,34 \mathrm{~B}$ & $0,30 \mathrm{~A}$ \\
\hline
\end{tabular}

Médias seguidas de letras distintas diferem entre si, pelo teste $\mathrm{F}$, ao nível de 5\% de probabilidade. $\mathrm{CV}=84,38 \%$

Relacionando-se corredor com período do dia, observou-se que a concentração de $\mathrm{NH}_{3}$ aumenta de intensidade no decorrer do dia, atingindo o maior valor às 18 horas, e observou-se que os corredores central e sul ficaram com níveis de $\mathrm{NH}_{3}$ maiores em determinados períodos do dia em relação ao corredor norte (Tabela 5), devido ao fato de o vento predominante ser da direção nordeste e a difusão dos gases seguir o fluxo de convecção do ar (HELLICKSON \& WALKER, 1983).

Os valores médios de concentração de amônia observados no interior do galpão são inferiores aos níveis recomendados pela NR-15 (MTE, 1990), cujo limite de tolerância é de 20 ppm para exposição de 8 horas diárias de trabalho. Estes valores também são menores que o limite de 20 ppm, valor a partir do qual o animal se torna suscetível a doenças (WATHES et al., 1998; NÄ̈̈S et al., 2007), e que corroboram os valores relatados por vários autores (NÄ̈̈S et al., 2007; VITORASSO \& PEREIRA, 2009; FURTADO et al., 2010; MENEGALI et al., 2012). 
TABELA 5. Valores médios de concentração de $\mathrm{NH}_{3}$ (ppm) nos corredores ao longo do período de avalição. Mean $\mathrm{NH}_{3}$ concentration ( $\mathrm{ppm}$ ) in the alleys throughout the evaluation period.

\begin{tabular}{clll}
\hline \multirow{2}{*}{ Período } & \multicolumn{3}{c}{ Corredor } \\
\cline { 2 - 4 } & Norte & Central & Sul \\
\hline $\mathbf{0 8 : 0 0}$ & 0,07 a A & 0,13 a A & 0,17 a A \\
$\mathbf{1 0 : 0 0}$ & 0,00 a A & 0,02 a A & $0,13 \mathrm{ab} \mathrm{A}$ \\
$\mathbf{1 2 : 0 0}$ & 0,15 a A & 0,43 ab B & $0,57 \mathrm{abc} \mathrm{B}$ \\
$\mathbf{1 4 : 0 0}$ & 0,17 a A & 0,39 ab B & $0,58 \mathrm{abc} \mathrm{B}$ \\
$\mathbf{1 6 : 0 0}$ & 0,19 a A & $0,38 \mathrm{ab} \mathrm{A}$ & $0,63 \mathrm{ac} \mathrm{B}$ \\
$\mathbf{1 8 : 0 0}$ & 0,45 a A & $0,75 \mathrm{~b} \mathrm{~B}$ & $0,87 \mathrm{~cd} \mathrm{~B}$ \\
$\mathbf{2 0 : 0 0}$ & 0,25 a A & $0,30 \mathrm{ab} \mathrm{A}$ & $0,38 \mathrm{abc} \mathrm{A}$ \\
\hline
\end{tabular}

Médias seguidas de letras distintas, maiúsculas na linha e minúsculas na coluna, diferem entre si, pelo teste de Tukey, ao nível de 5\% de probabilidade. $\mathrm{CV}=80,06 \%$

Com relação à concentração de $\mathrm{CO}_{2}$, verificou-se interação significativa $(\mathrm{p}<0,01$, teste $\mathrm{F}$ ) entre os tratamentos, tela x corredor e corredor x período. De acordo com a Tabela 6, o uso da tela para cercar o perímetro externo do galpão fez com que os níveis médios de $\mathrm{CO}_{2}$ ficassem superiores apenas no corredor sul. Os corredores central e sul apresentaram os maiores valores médios de $\mathrm{CO}_{2}$, devido ao fato de o vento predominante ser da direção nordeste (HELLICKSON \& WALKER, 1983), assim como para os níveis de $\mathrm{NH}_{3}$.

TABELA 6. Valores médios de concentração de $\mathrm{CO}_{2}(\mathrm{ppm})$ nos tratamentos com e sem tela $\mathrm{x}$ corredor. Mean $\mathrm{CO}_{2}$ concentration $(\mathrm{ppm})$ in the treatments with and without screen $\mathrm{x}$ alley.

\begin{tabular}{ccc}
\hline \multirow{2}{*}{ Corredor } & \multicolumn{2}{c}{ Tela } \\
\cline { 2 - 3 } & Com & Sem \\
\hline Norte & 409,7 a A & 407,7 a A \\
Central & 468,6 c A & 466,6 b A \\
Sul & 480,6 b B & 462,3 b A \\
\hline
\end{tabular}

Médias seguidas de letras distintas, maiúsculas na linha e minúsculas na coluna, diferem entre si, pelo teste de Tukey, ao nível de 5\% de probabilidade. $\mathrm{CV}=7,04 \%$

As concentrações de dióxido de carbono foram superiores nos corredores central e sul, em todos os períodos do dia (Tabela 7). Citando a questão da insalubridade, os valores médios de concentração de $\mathrm{CO}_{2}$ observados dentro do galpão estão abaixo do limite de tolerância de 3.900 ppm que a norma NR-15 (MTE, 1990) preconiza para exposição de 8 horas diárias de trabalho. Os valores observados neste trabalho assemelham-se aos relatados por LIMA (2011) em trabalho realizado com frangos de corte.

Relacionando-se corredor com período do dia, observou-se que a concentração de $\mathrm{CO}_{2}$ aumenta no primeiro e nos dois últimos períodos avaliados (8; 18 e 20 horas), e este comportamento deve-se às baixas temperaturas ocorridas nestes períodos (MENEGALI et al., 2009). 
TABELA 7. Valores médios de concentração de $\mathrm{CO}_{2}$ (ppm) nos corredores ao longo do período de avaliação. Mean $\mathrm{CO}_{2}$ concentration (ppm) in the alleys throughout the evaluation period.

\begin{tabular}{cccc}
\hline \multirow{2}{*}{ Período } & \multicolumn{3}{c}{ Corredor } \\
\cline { 2 - 4 } & Norte & Central & Sul \\
\hline 08:00 & $437,1 \mathrm{~b} \mathrm{~A}$ & $500,9 \mathrm{c} \mathrm{B}$ & $490,5 \mathrm{c} \mathrm{B}$ \\
$\mathbf{1 0 : 0 0}$ & 389,4 a A & $444,4 \mathrm{a} \mathrm{B}$ & $449,8 \mathrm{~b} \mathrm{~B}$ \\
$\mathbf{1 2 : 0 0}$ & 354,8 a A & $402,7 \mathrm{~b} \mathrm{~B}$ & $405,9 \mathrm{a} \mathrm{B}$ \\
$\mathbf{1 4 : 0 0}$ & $369,5 \mathrm{a} \mathrm{A}$ & $416,5 \mathrm{ab} \mathrm{B}$ & $408,2 \mathrm{a} \mathrm{B}$ \\
$\mathbf{1 6 : 0 0}$ & $378,0 \mathrm{a}$ A & $436,6 \mathrm{ab} \mathrm{B}$ & $441,5 \mathrm{ab} \mathrm{B}$ \\
$\mathbf{1 8 : 0 0}$ & $438,8 \mathrm{~b} \mathrm{~A}$ & $518,0 \mathrm{~cd} \mathrm{~B}$ & $532,1 \mathrm{~d} \mathrm{~B}$ \\
$\mathbf{2 0 : 0 0}$ & $493,3 \mathrm{c} \mathrm{A}$ & $554,1 \mathrm{~d} \mathrm{~B}$ & $572,3 \mathrm{~d} \mathrm{~B}$ \\
\hline
\end{tabular}

Médias seguidas de letras distintas, maiúsculas na linha e minúsculas na coluna, diferem entre si, pelo teste de Tukey, ao nível de 5\% de probabilidade. $\mathrm{CV}=6,05 \%$

\section{CONCLUSÕES} instalação.

O uso de tela para cercar o perímetro do galpão não alterou o nível de ruído dentro da

As concentrações de amônia foram superiores na região cercada por tela, e as concentrações de $\mathrm{CO}_{2}$ foram superiores apenas no corredor sul da região cercada por tela. Contudo, não foram observadas concentrações de $\mathrm{NH}_{3}$ e $\mathrm{CO}_{2}$ que oferecessem riscos à saúde das aves e dos trabalhadores.

Portanto, o uso de tela PEAD (com malha de 2,0 cm de diâmetro) para cercar o perímetro externo de galpões comerciais tipo californiano para criação de poedeiras da linhagem $H y$ line $W$-36 não apresentou limitações em relação ao ambiente aéreo e sonoro.

\section{AGRADECIMENTOS}

Os autores expressam seus agradecimentos à FAPEMIG, CAPES, CNPq e ASA (Aviário Santo Antônio), pelo apoio a esta pesquisa.

\section{REFERÊNCIAS}

BRAVALHERI, A. C.; BERNARDO, L. A.; MIRANDA, M. A. M.; ANGELO, T. N.; PARAHYBA, V. E. S. Poluição sonora em ambientes da Unicamp. Revista Ciências do Ambiente On-Line. Campinas, v.6, n.1, 2010. Disponível em: <http://sistemas.ib.unicamp.br/be310/>. Acesso em: 11 ago. 2013.

CARVALHO, C. C. S.; SOUZA, C. F.; TINOCO, I. F. F.; VIEIRA, M. F. A.; MINETTE, L. J. Segurança, saúde e ergonomia de trabalhadores em galpões de frangos de corte equipados com diferentes sistemas de abastecimento de ração. Engenharia Agrícola, Jaboticabal, v. 31, n.3, p.438447, maio/jun. 2011.

FURTADO, D. A.; MOTA, J. K.; NASCIMENTO, J. W.; SILVA, V. R.; TOTA, L. C. A. Produção de ovos de matrizes pesadas criad as sob estresse térmico. Revista Brasileira de Engenharia Agrícola e Ambiental, Campina Grande, v.15, n.7, p.748-753, jul. 2011.

FURTADO, D. A.; ROCHA, H. P.; NASCIMENTO, J. W. B.; SILVA, J. H. V. Índices de conforto térmico e concentração de gases em galpões Avícolas no semiárido paraibano. Engenharia Agrícola, Jaboticabal, v.30, n.6, p.993-1002, nov./dez. 2010.

HELLICKSON, M. A.; WALKER, J. N. Ventilation of agricultural structures. St. Joseph: American Society of Agricultural Engineers, 1983. 213 p.

LIMA, K. A. O. Avaliação de sistemas de ventilação mecanizada por pressão positiva e negativa utilizados na avicultura de corte. 2011. 189 f. Tese (Doutorado em Engenharia Agrícola) -

Faculdade de Engenharia Agrícola, Universidade Estadual de Campinas, Campinas, 2011. 
MATTOS, J. M. Avaliação das instalações em aviários de postura conforme aspectos de conforto térmico na região de bastos. 2007. 57 f. Dissertação (Mestrado em Agronomia) - Faculd ade de Ciências Agronômicas, Universidade Estadual Paulista, Botucatu, 2007.

MENEGALI, I.; TINÔCO, I. F. F.; BAÊTA, F. C.; CECON, P. C.; GUIMARÃES, M. C. D. C.; CORDEIRO, M. B. Ambiente térmico e concentração de gases em instalações para frangos de corte no período de aquecimento. Revista Brasileira de Engenharia Agrícola e Ambiental, Campina Grande, v.13, p.984-990, 2009. Suplemento.

MENEGALI, I.; TINÔCO, I. F. F.; ZOLNIER, S.; CARVALHO, C. D.; GUIMARÃES, M. C. D. C. Influence of different systems of minimum ventilation on air quality in broiler houses. Engenharia Agrícola, Jaboticabal, v.32, n.6, p.1024-1033, nov/dez. 2012.

MAPA. Ministério da Agricultura, Pecuária e Abastecimento. Instrução Normativa No 36, de 6 de dezembro 2012. Estabelece os procedimentos para Registro, Fiscalização e Controle de estabelecimentos avícolas de Reprodução e Comerciais. Diário Oficial da União, Brasília, DF, 7 dez. 2012. Seção 1, p. 25.

MAPA. Ministério da Agricultura, Pecuária e Abastecimento. Instrução Normativa $n^{\circ}$ 56, de 4 de dezembro 2007. Estabelece os procedimentos para Regis tro, Fiscalização e Controle de estabelecimentos a vícolas de Reprodução e Comerciais. Diário Oficial da União, Brasília, DF, 6 dez. 2007. Seção 1, p. 11.

MOURA, D. J.; BUENO, L. G. F.; LIMA, K. A. O.; CARVALHO, T. M. R.; MAIA, A. P. A. Strategies and facilities in order to improve animal welfare. Revista Brasileira de Zootecnia, Viçosa, MG, v.39, p.311-316, jul. 2010. Suplemento Especial.

MTE - MINISTÉRIO DO TRABALHO E EMPREGO. Normas Regulamentadora de segurança e saúde no trabalho (NR-15): atividades e operações insalubres. Brasília, 1990. Disponível em: < http://portal.mte.gov.br/legislacao/norma-regulamentadora-n-15-1.htm>. Acesso em: abril de 2013.

NÄÄS, I. A.; MIRAGLIOTTA, M. Y.; BARACHO, M. S.; MOURA, D. J. Ambiência aérea em alojamento de frangos de corte: poeira e gases. Engenharia Agrícola, Jaboticabal, v.27, n.2, p.326335, maio/ago. 2007.

NÄÄS, I. A.; MIRAGLIOTTA, M. Y.; BARACHO, M. S. Níveis de Ruídos na Produção de Matrizes Pesadas - Estudo de Caso. Revista Brasileira Ciência Avícola, Campinas, v.3, n.2, maio/ago. 2001.

NASCIMENTO, R. G; GODOY, R. M. B.; SOUTO JUNIOR, C. A.; UEHARA, G. T. Avaliação da poluição sonora na Unicamp. Revista Ciências do Ambiente On-line, Campinas, v. 3, n. 1, p.60-64, fev. 2007. Disponível em: <http://sistemas.ib.unicamp.br/be310/>. Acesso em: 12 ag. 2013.

ROCHA, H. D.; FURTADO, D.; NASCIMENTO, J. D.; SILVA, J. H. Índ ices bioclimáticos e produtivos em diferentes galpões a vícolas no semiárido paraibano. Revista Brasileira de Engenharia Agrícola e Ambiental, Campina Grande, v. 14, n. 12, p.1330-1336, dez. 2010.

SARAZ, J. A. O.; TINÔCO, I. F. F.; PAULA, M. O.; PEIXOTO, R. F.; GATES, R. Elaboración y evaluación de tejas de concreto en arcilla expandida para uso como coberturas de estructuras pecuarias. Revista Facultad Nacional de Agronomia, Medellín, v.63, p.5651-5660, 2010.

SAS Institute. SAS/STATTM SAS user's guide for windows environment. 9.3 ed. Cary : SAS Institute, 2012.

VIGODERIS, R.B.; CORDEIRO, M.B.; TINÔCO, I.F.F.; MENEGALI, I.; SOUZA JÚNIOR, J.P.;

HOLANDA, M.C.R. Avaliação do uso de ventilação mínima em galpões avícolas e de sua influência no desempenho de aves de corte no período de inverno. Revista Brasileira de Zootecnia, Viçosa, MG, v.39, n.6, p.1381-1386, 2010.

VITORASSO, G; PEREIRA, D. F. Análise comparativa do ambiente de aviários de postura com diferentes sistemas de acond icionamento. Revista Brasileira de Engenharia Agrícola e Ambiental, 
Campina Grande, v.13, n.6, p.788-794, nov/dez. 2009.

WATHES, C. M.; HOLDEN, M. R.; SNEATH, R. W.; WHITE, R. P.; PHILLIPS, V. R.

Concentrations and emissions rates of aerial ammonia, nitrous oxide, methane, carbon dioxide, dust and endotoxin in UK broiler and layer houses. British Poultry Science, London, v.38, n.1, p.14-28, 1998.

YANAGI JUNIOR, T.; AMARAL, A. G; TEIXEIRA, V. H.; LIMA, R. R. Caracterização espacial do ambiente termoacústico e de iluminância em galpão comercial para criação de frangos de corte. Engenharia Agrícola, Jaboticabal, v.31, n.1, p.1-12, jan/fev. 2011.

YANAGI JUNIOR, T.; SCHIASSI, L.; ROSSONI, D. F.; PONCIANO, P. F.; \& LIMA, R. R. D. Spatial variability of noise level in agricultural machines. Engenharia Agrícola, Jaboticabal, v.32, n.2, p.217-225, mar/abr. 2012. 